\title{
Type 1 autoimmune pancreatitis
}

\author{
Yoh Zen ${ }^{*}$, Dimitrios P Bogdanos ${ }^{1}$ and Shigeyuki Kawa ${ }^{2}$
}

\begin{abstract}
Before the concept of autoimmune pancreatitis (AIP) was established, this form of pancreatitis had been recognized as lymphoplasmacytic sclerosing pancreatitis or non-alcoholic duct destructive chronic pancreatitis based on unique histological features. With the discovery in 2001 that serum IgG4 concentrations are specifically elevated in AIP patients, this emerging entity has been more widely accepted. Classical cases of AIP are now called type 1 as another distinct subtype (type 2 AIP) has been identified. Type 1 AIP, which accounts for 2\% of chronic pancreatitis cases, predominantly affects adult males. Patients usually present with obstructive jaundice due to enlargement of the pancreatic head or thickening of the lower bile duct wall. Pancreatic cancer is the leading differential diagnosis for which serological, imaging, and histological examinations need to be considered. Serologically, an elevated level of IgG4 is the most sensitive and specific finding. Imaging features include irregular narrowing of the pancreatic duct, diffuse or focal enlargement of the pancreas, a peri-pancreatic capsule-like rim, and enhancement at the late phase of contrast-enhanced images. Biopsy or surgical specimens show diffuse lymphoplasmacytic infiltration containing many $\operatorname{lgG} 4^{+}$plasma cells, storiform fibrosis, and obliterative phlebitis. A dramatic response to steroid therapy is another characteristic, and serological or radiological effects are normally identified within the first 2 or 3 weeks. Type 1 AlP is estimated as a pancreatic manifestation of systemic lgG4related disease based on the fact that synchronous or metachronous lesions can develop in multiple organs (e.g. bile duct, salivary/lacrimal glands, retroperitoneum, artery, lung, and kidney) and those lesions are histologically identical irrespective of the organ of origin. Several potential autoantigens have been identified so far. A Th2dominant immune reaction and the activation of regulatory T-cells are assumed to be involved in the underlying immune reaction. IgG4 antibodies have two unique biological functions, Fab-arm exchange and a rheumatoid factor-like activity, both of which may play immune-defensive roles. However, the exact role of IgG4 in this disease still remains to be clarified. It seems important to recognize this unique entity given that the disease is treatable with steroids.
\end{abstract}

Keywords: IgG4, diagnosis, IgG4-related disease, pathology, pathogenesis

\section{Background}

The entity "autoimmune pancreatitis (AIP)" was first proposed by Yoshida et al [1] in 1995, who described a case of steroid-responsive pancreatitis. That report described a case of a diffuse enlargement of the pancreas and irregular narrowing of the pancreatic duct, serologically associated with hyper- $\gamma$-globulinemia and anti-nuclear antibody (ANA) positivity [1]. The presence of pancreatitis, features of autoimmune disease, and responsiveness to immunosupression led to the connotation of AIP [1]. The term of AIP has been since used by other groups, and is now accepted worldwide. However, the first evidence of

\footnotetext{
* Correspondence: yoh.zen@kcl.ac.uk

'Institute of Liver Studies, King's College Hospital and King's College London School of Medicine, Denmark Hill, London SE5 9RS, UK

Full list of author information is available at the end of the article
}

features compatible with AIP was described by Sarles et al [2]. in 1961, who reported the case series of an unusual pancreatitis associated with obstructive jaundice and hyper- $\gamma$-globulinemia, suggestive of an underlying autoimmune process. This form of pancreatitis was recognized as lymphoplasmacytic sclerosing pancreatitis or non-alcoholic duct destructive chronic pancreatitis based on distinct histological features in the 1990s [3,4]. Another landmark paper was published in the New England Journal of Medicine in 2001, where Hamano et al [5]. reported that serum IgG4 levels are specifically elevated in Japanese patients with AIP. An increase of IgG4 levels in AIP cohorts has been also confirmed in Western and Eastern countries [6,7]. The discovery of hyper-IgG4 has strengthened the concept of AIP. In addition, clinical and histological reviews of AIP patients provided evidence that AIP
C Biomed Central

() 2011 Zen et al; licensee BioMed Central Ltd. This is an Open Access article distributed under the terms of the Creative Commons Attribution License (http://creativecommons.org/licenses/by/2.0), which permits unrestricted use, distribution, and reproduction in any medium, provided the original work is properly cited. 
can be classified into 2 types: IgG4-related and non-related $[8,9]$.

IgG4 is not only a serological marker but is also histologically detectable. The demonstration of pancreatic infiltration by IgG4 ${ }^{+}$plasma cells reported in 2002 [10] was followed by studies reporting similar sclerosing lesions in various organs $[11,12]$. Hence, a new systemic disease entity, "IgG4-related disease", is proposed. This is based on the fact that synchronous or metachronous lesions can develop in multiple organs and the lesions are histologically identical irrespective of the organ of origin $[13,14]$. IgG4-related AIP is considered a pancreatic manifestation of IgG4-related disease.

\section{Subtypes and histopathology of AIP}

Recent papers have provided evidence that there are two subtypes of AIP with different clinical and histological characteristics $[8,9,15,16]$. The classical form is called type 1 AIP, which is associated with elevated serum IgG4 levels and tissue infiltration by $\operatorname{IgG4} 4^{+}$plasma cells $[15,16]$. Type 2 AIP, which is not related to IgG4, was identified based on the histological features of neutrophilic infiltration into the pancreatic duct epithelium (granulocytic epithelial lesion: GEL) $[17,18]$. Type 1 appears to be the most predominant form of AIP. Clinical and histological features of both subtypes are summarized in Table 1. A Japanese nationwide study revealed that the annual number of patients with type 1 AIP is 0.71 per 100,000 , which accounts for $2 \%$ of patients with chronic pancreatitis [19]. The exact prevalence of type 2 AIP is still unknown but it is less common than that of type 1 AIP $[9,15]$.

Type 1 and type 2 AIP share some histological features including diffuse lymphoplasmacytic infiltration and fibrosis, but these are classifiable based on purely histological grounds $[17,18,20]$. The pathological synonym of type 1 AIP is lymphoplasmacytic sclerosing pancreatitis (LPSP) which is characterized by a predominantly lobular involvement with "storiform" fibrosis, obliterative phlebitis, and infiltration by many IgG4 $4^{+}$plasma cells (Figure $1 \mathrm{~A}-\mathrm{D})[3,20]$. A diagnostic feature of type 2 AIP is GEL

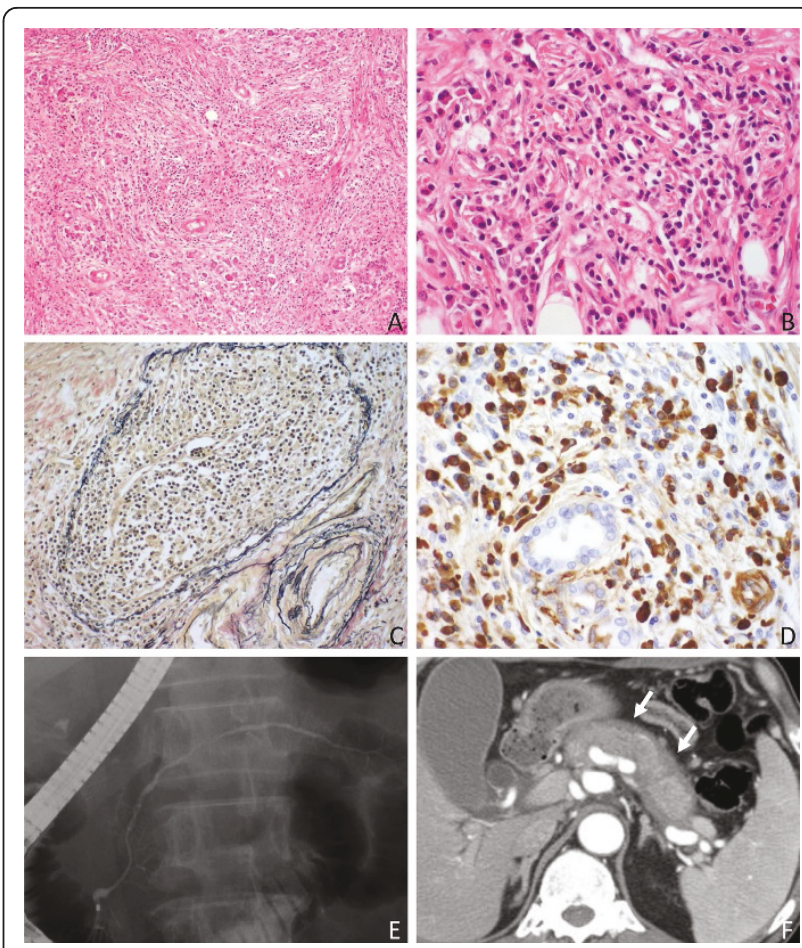

Figure 1 Histological and radiological features of type 1 AIP. A Pancreas is inflamed with inflammatory cell infiltration and storiform fibrosis $(H \& E, \times 100)$. B: Inflammatory cells consist of predominantly lymphocytes and plasma cells, and occasional eosinophils (H\&E, $\times 400$ ). C: A vein branch is obliterated by sclerosing inflammation (obliterative phlebitis) (Elastica van Gieson, ×200). D: Many IgG4+ plasma cells are identified (lgG4 immunostaining, $\times 400)$. E: ERCP shows diffuse irregularity of the pancreatic duct. F: The pancreas is diffusely enlarged with a peri-pancreatic rim (arrows) (contrastenhanced (T).

with or without lobular neutrophilic infiltration $[17,18,20]$. IgG4 ${ }^{+}$plasma cells appear to be less conspicuous in type 2 AIP [21]. That is, the most important histological feature is IgG4 $4^{+}$plasma cell infiltration in type 1 and neutrophilic epithelial injury in type 2 AIP. Given that the clinical features and pathogenesis of type 2 AIP are poorly defined, this review will only discuss type 1 AIP.

Table 1 Comparison of type 1 and type 2 autoimmune pancreatitis (AIP)

\begin{tabular}{lll}
\hline & Type 1AIP & Type 2 AIP \\
\hline Age & Adult & Child and adult \\
Sender & Predominantly male & Almost equal \\
Histology & Elevated & Normal \\
$\quad$ Histological nomenclature & Lymphoplasmacytic sclerosing pancreatitis (LPSP) & \\
$\quad$ lgG4+ plasma cells & Many & Idiopathic duct-centric pancreatitis \\
$\quad$ Granulocytic epithelial lesion & Absent & Rare \\
Relapse rate & High & Present \\
Extra-pancreatic lesions & IgG4-related disease as shown in Table 2 & Low \\
\hline
\end{tabular}




\section{Clinical features}

Type 1 AIP predominantly affects adult males with $>90 \%$ of patients being more than 40 years of age. There is a male preponderance, with a male/female ratio of 3-4:1 $[19,22,23]$. The major symptom at onset is obstructive jaundice, which is caused by an enlargement of the pancreatic head or thickening of the bile duct wall [24-26]. Blood tests results include increased bilirubin and cholestatic enzymes, transaminasaemia, and occasionally elevation of carbohydrate antigen 19-9 (CA19-9) [24]. These findings mimic those found in pancreatic cancer, and indeed $2-3 \%$ of pancreatic head lesions surgically resected for suspected malignancy turned out to be type 1 AIP by histological examination $[27,28]$. Contrary to pancreatic cancer, the jaundice of type 1 AIP patients is quickly improved by steroid therapy or sometimes subsides spontaneously. Severe abdominal pain is a rare subjective symptom different from ordinary chronic pancreatitis, such as alcoholic pancreatitis [24]. In over half of cases, levels of pancreatic enzymes are mildly or moderately elevated [24]. Diabetes mellitus is a common complication, seen in about half of the patients, the majority showing type II diabetes. Steroid therapy can ameliorate glucose intolerance in some patients along with an improvement of pancreatitis, but may aggravate the diabetes in others, particularly older patients $[29,30]$. Diarrhoea due to impaired exocrine function is rare, but bentiromide or secretin testing shows somewhat impaired exocrine function [30]. This can be improved to some extent by steroid therapy [31]. Patients may have symptoms related to extra-pancreatic lesions such as lacrimal and salivary gland enlargement [13], cough or dyspnea caused by respiratory lesions [32], lumbago caused by hydronephrosis and retroperitoneal fibrosis [10], and polyuria caused by prostatic lesions [33-35].

\section{Serological characteristics}

Elevated serum levels of IgG4 (> $135 \mathrm{mg} / \mathrm{dL})$ are seen in more than $90 \%$ of patients $[5,24]$. This is the most sensitive and specific diagnostic test for type 1 AIP, with $95 \%$ sensitivity, 97\% specificity, and 97\% accuracy for discrimination from pancreatic cancer [5]. It is also useful for determining disease activity and predicting relapse [36-38]. Other commonly detectable immunological features include elevation of IgG (70\%), $\gamma$-globulin (60\%), and IgE $(33 \%)[39,40]$. Rheumatoid factor and ANA are also detectable in 30 to $40 \%$ of patients [39,40]. However, disease-specific autoantibodies such as anti SS-A/Ro and SS-B/La or anti-mitochondrial antibodies are extremely uncommon [24]. These findings suggest that patients with type 1 AIP can produce various autoantibodies but these antibodies lack disease specificity.

Complement C3 and C4 are reduced in 36\% of patients, particularly those with high levels of circulating immune complexes, suggesting immune-mediated complement activation [41]. The complement activation system consists of classical, alternative, and mannosebinding lectin pathways. Given that the latter two seem less activated in type 1 AIP, the classical pathway may be predominantly operating [41].

The exact role of IgG4 in IgG4-related disease remains elusive. IgG4-type pathogenic autoantibodies can induce tissue damage, as in the case of anti-desmoglein 3 autoantibody in pemphigus vulgaris [42]. Few reports regarded IgG4-type autoantibodies as pathogenic in type 1 AIP. IgG4 was recently discovered to have two outstanding characteristics, Fab-arm exchange [43] and rheumatoid factor-like activity [44], both of which may play immunedefensive roles by eliminating IgG4-bound immune complex from the circulation. Fab-arm exchange results in bispecific antigen binding, which interferes with the formation of IgG4-associated immune complexes [44]. It was also demonstrated that IgG4 can bind to another IgG of any subclass via Fc-Fc interaction, and this IgG4 Fc-Fc interaction may represent an intermediate state of the Fab-arm exchange reaction [44-47], although the role of this function remains unclear. Further studies are needed to clarify whether IgG4 has beneficial or detrimental effects in IgG4-related disease including type 1 AIP.

\section{Radiological features}

An important radiological feature is irregular narrowing of the pancreatic duct which can be detected by endoscopic retrograde cholangiopancreatography (ERCP) or magnetic resonance cholangiopancreatography (MRCP) (Figure 1E) $[48,49]$. The former is more sensitive but the latter is more widely used for diagnosis given its less invasive nature. Complete obliteration of the main pancreatic duct with dilatation of the distal duct, which is commonly found in patients with pancreatic cancer, is atypical in type 1 AIP.

Characteristic features of ultrasonography (US), computed tomography $(\mathrm{CT})$ and magnetic resonance imaging (MRI) include diffuse or focal pancreatic enlargement, a peri-pancreatic capsule-like rim, enhancement at the late phase of contrast-enhanced images, and abnormal signal intensity on MRI [50-52]. Diffuse enlargement of the pancreas with loss of the cobble-stone architecture of the pancreatic surface is a common finding of type 1 AIP in all imaging modalities [50-52]. US characteristically shows diffuse low-echoic change with high-echo spots which was originally called "sausage-like" swelling [53]. The enlarged pancreas is associated with a capsule-like, low-density rim which appears more evident on contrast-enhanced CT or MRI, particularly at the early phase (Figure 1F) [50-52]. This is a radiological finding representing a fibrosing process extending into peri-pancreatic adipose tissue [50]. In contrast to normal pancreatic parenchyma which shows enhancement at the early phase of contrast-enhanced 
images, type 1 AIP is characterized by enhancement at the late phase (a delayed enhancement) [50-52]. Signal intensity of type 1 AIP on T1-weighted MRI is decreased compared to non-affected pancreatic parenchyma, sometimes appearing even lower than that of the liver [50]. T2weighted MRI scans show increased signal intensity. Rare radiological findings include multiple small nodules [54], stone formation [55], and cystic degeneration [56], the latter two being more common at the late stage.

It is also important to identify extra-pancreatic lesions, the presence of which is indicative of type 1 AIP and makes a diagnosis of pancreatic cancer less likely. F-18 fluorodeoxyglucose positron emission tomography (FDGPET) is also useful for this purpose given that extra-pancreatic lesions are usually positive for FDG-PET the same as type 1 AIP [57-59]. Gallium-67 scintigraphy is another modality to detect extra-pancreatic lesions, accumulation at the pulmonary hilum being a characteristic finding for type 1 AIP patients [60]. In our experience, extra-pancreatic lesions are sometimes detected at unexpected sites by FDG-PET or systemic CT/MRI.

\section{Diagnosis}

A number of diagnostic criteria for type 1 AIP have been proposed so far from Japan, South Korea, and the United States (HISORt criteria of the Mayo Clinic) [36,37,61-63]. Despite minor differences among sites, diagnostic criteria include imaging features, serological abnormalities, and histological findings. Patients with typical imaging features (diffuse pancreatic enlargement with an irregular/narrow pancreatic duct) and elevated serum IgG4 levels, with or without other non-specific autoimmune abnormalities (e.g., ANA or hyper-IgG), fulfill all criteria. In a situation in which serological features cannot be detected, histological evidence of LPSP (e.g., diffuse lymphoplasmacytic infiltration, storiform fibrosis, and obliterative phlebitis) needs to be confirmed by biopsies. Immunostaining of IgG4 is also useful with $\geq 10 \mathrm{IgG4}^{+}$plasma cells per high-power field in biopsy samples being supportive of LPSP [64]. However, it should be noted that $\geq 10 \mathrm{IgG}^{+}$plasma cells can be rarely identified in biopsy specimens from pancreatic cancer [64].

There are still pros and cons with steroid trials approved based on most diagnostic criteria except the Japanese ones [36,37,61-63]. Given that pancreatic swelling dramatically improves even after a few weeks of steroid therapy, steroid trials would be a useful diagnostic test. Immunosupression must only be considered under restricted conditions, given that pancreatic cancer is the most likely differential diagnosis of type 1 AIP.

Surgically resected specimens showing typical features of LPSP with numerous IgG4 ${ }^{+}$plasma cells can be diagnosed as type 1 AIP based purely on histological grounds. This is particularly important for retrospective reviews of cases without sufficient serological and radiological data. It is questionable whether or not findings of a needle biopsy are sufficient for the diagnosis. If a diagnosis of type 1 AIP is histologically suggested, imaging and serological data should be reviewed. In our experience, histological findings of type 1 AIP in the absence of consistent radiological or serological features are extremely unlikely.

\section{Treatment}

An administration of an oral steroid is a standard treatment for type 1 AIP $[65,66]$. Most patients respond well to immunosupression with significant improvement of radiological and serological abnormalities [29,31]. Spontaneous remission can also occur particularly in patients with inactive disease. Normally, patients are started on $30-40 \mathrm{mg}$, or $0.6 \mathrm{mg} / \mathrm{kg}$, per day of prednisolone for 2-4 weeks with careful monitoring of clinical features, and serological and imaging findings $[67,68]$. Amelioration of the clinical features is usually observed within 2 weeks, and clinical remission is frequently seen within 4 weeks. Thereafter, the dosage is reduced (tapering by $5 \mathrm{mg} /$ day every 2 weeks over 2-3 months, to $2.5-7.5 \mathrm{mg}$ per day), and a maintenance dose is required for 6 months to 3 years [67].

Relapse can be defined as symptomatic or radiologically detectable disease recurrence in not only the pancreas but also extrapancreatic organs. Biochemical or serologic recurrence alone is not considered relapse. Given that most relapses are observed within the first 3 years, patients with active disease (e.g. extremely high levels of serum IgG4 or multiple organ lesions) require prolonged treatment [65-67]. Cessation of maintenance therapy can be considered after six months in those cases with inactive disease. If steroid therapy is ineffective, clinical and serological data need to be reviewed in order to definitively exclude pancreatic malignancy. Other therapies which have been reported to be effective for highly active or refractory type 1 AIP are steroid pulse therapy [69], immuno-suppression with azathioprine or 6-mercaptopurine [70], and rituximab administration [71].

Treatment by resection is not recommended for type 1 AIP. However, even in large pancreatic centres, the surgical approach is still unavoidable for minor cases, for which malignancy cannot be entirely excluded. Surgeries can be also considered for large pseudocysts, which are rarely associated with type 1 AIP $[72,73]$. Interestingly, one paper described that recurrent rate after surgery appears lower than that after steroid therapy [15].

\section{Extra-pancreatic lesions and IgG4-related disease}

Type 1 AIP is commonly associated with the involvement of other organs, the incidence of which was reported to be approximately $50 \%$ to $70 \%[9,15]$. Type 1 AIP is now considered as a pancreatic manifestation of systemic 
IgG4-related disease, and extra-pancreatic lesions similar to those seen in the pancreas, can develop in the absence of pancreatic abnormalities [74,75]. Extra-pancreatic lesions may be identified at the same time as type 1 AIP or may appear afterward particularly during tapering doses of steroid or after completion of steroid therapy. As mentioned, extra-pancreatic lesions can precede the episode of type 1 AIP. IgG4-related disease has been identified in various organs based on histological evidence of IgG4 $4^{+}$plasma cell infiltration, steroid responsiveness, or high serum IgG4 concentrations. Most IgG4related lesions share clinicopathological characteristics irrespective of the organ of origin, but several organspecific features have been identified [76]. As shown in Table 2 a variety of organs can be involved in IgG4related disease. Almost all lesions have probably been discovered, but the possibility of an IgG4-related disease always needs to be considered for an unusual lesion at any site if it appears during the follow up in patients with known IgG4-related disease.

\section{Pathogenesis}

Several genetic susceptibility factors for type 1 AIP have been identified as summarized in Table 3[77-81]. Findings obtained in one ethnic group are not always confirmed in patients in other groups, which raises the possibility that genetic susceptibility factors may be different among ethnic groups.

In view of the autoimmune hypothesis surrounding IgG4-related disease, a series of studies have investigated the specificity of autoantibody responses in patients with type 1 AIP leading to the identification of several autoantigens. Antibodies against lactoferrin and carbonic anhydrase (CA) II are most frequently detected in type 1 AIP (73\% and 54\%, respectively) [82]. Anti-CA-IV antibodies were also detected in $34 \%$ of patients [83]. Other potential autoantigens include pancreatic secretory trypsin inhibitor and trypsinogens $[84,85]$. However, it remains to be seen whether IgG4 is an autoantibody in type 1 AIP or is overexpressed secondary in response to an unknown primary inflammatory stimulus.

Interestingly, there is significant homology between human CA-II and alpha-CA of Helicobacter pylori $(H$. pylori) [86]. More recently, it was found that $94 \%$ of patients with type 1 AIP had antibodies against plasminogen-binding protein of $H$. pylori [87]. The amino acid sequence of this protein exhibits homology with that of the ubiquitin-protein ligase E3 component n-recognin 2 which is expressed in pancreatic acinar cells. These two studies raise the possibility that $H$. pylori infection might trigger type 1 AIP in genetically predisposed subjects via molecular mimicry $[86,87]$. However, the latter study has reported elevated IgG4 in only $53 \%$ of the patients making
Table 2 A list of major IgG4-related disease in various organs

\begin{tabular}{|c|c|}
\hline Organ & Manifestation \\
\hline Pituitary gland & Hypophysitis \\
\hline Meningis & Pachymeningitis \\
\hline Lacrimal gland & Chronic sclerosing dacryoadenitis (Mikulicz's disease) \\
\hline Salivary gland & Chronic sclerosing sialadenitis (Küttner's tumour) \\
\hline \multirow[t]{6}{*}{ Lymph node } & Lymphadenopathy with 5 histological subtypes \\
\hline & - Multicentric Castleman disease-like (type I) \\
\hline & - Follicular hyperplasia (type II) \\
\hline & - Interfollicular expansion (type III) \\
\hline & $\begin{array}{l}\text { - Progressive transformation of germinal centre } \\
\text { (type IV) }\end{array}$ \\
\hline & - Nodal inflammatory pseudotumor (type V) \\
\hline Thyroid & Thyroiditis or hypothyroidism \\
\hline Skin & Pseudolymphoma \\
\hline Breast & Inflammatory pseudotumour or mastitis \\
\hline \multirow[t]{3}{*}{ Lung } & Inflammatory pseudotumour \\
\hline & Focal or diffuse interstitial pneumonia \\
\hline & Inflammation in bronchovascular bundles. \\
\hline Pleura & Nodular pleuritis \\
\hline Stomach & Chronic gastritis or ulcer \\
\hline Vater's ampulla & Pseudotumourous enlargement \\
\hline Pancreas & Type 1 autoimmune pancreatitis \\
\hline Bile duct & Sclerosing cholangitis \\
\hline Gallbladder & Lymphoplasmacytic sclerosing cholecystitis \\
\hline \multirow[t]{2}{*}{ Liver } & Inflammatory pseudotumour \\
\hline & Chronic active hepatitis (autoimmune hepatitis) \\
\hline Retroperitoneum & Retroperitoneal fibrosis \\
\hline \multirow[t]{2}{*}{ Aorta/artery } & Periaortitis/periarteritis \\
\hline & Inflammatory aneurysm \\
\hline Kidney & Tubulointerstitial nephritis \\
\hline Peripheral nerve & Perineural mass \\
\hline
\end{tabular}

it impossible to accurately estimate how many of these were type 1 AIP [87].

A T-helper (Th) 1 immune response has been considered to be predominant in type 1 AIP [82]. However, recent studies provided data in support of a Th2-predominant immune response in IgG4-related disease [88-92]. In addition, the number of regulatory $\mathrm{T}$-cells (Tregs) is characteristically increased in tissue-resident lymphocyte populations and whole blood of patients with type 1 AIP. The number of $\mathrm{CD} 4{ }^{+} \mathrm{CD} 25^{\text {high }}$ Tregs in blood was found significantly higher in patients with type 1 AIP than in patients with chronic pancreatitis and was correlated with the level of serum IgG4 [93]. In contrast, the number of naïve Tregs was significantly decreased. This has led to the assumption that hyporeactivity of naïve Tregs may be involved in the development of IgG4-related disease, whereas a hyper-reactivity of $\mathrm{CD} 4^{+} \mathrm{CD} 25^{\text {high }}$ Tregs could reflect IgG4-related disease progression [93]. Given that IL-10 has a major role 
Table 3 Genetic susceptibility factors for AIP and clinical implications.

\begin{tabular}{|c|c|c|c|}
\hline Gene & Polymorphism/genotype & Implication & Population \\
\hline \multirow[t]{2}{*}{ Human leukocyte antigen (HLA) } & $\mathrm{DRB} 1 * 0405, \mathrm{DQB} 1 * 0401$ & Increased disease susceptibility & Japanese \\
\hline & Non-aspartic acids at DQ $\beta 157$ & Increased relapse risk & Korean \\
\hline \multirow{4}{*}{ Cytotoxic T lymphocyte-antigen (CTLA-4) } & $+49 \mathrm{~A}$ & Increased disease susceptibility & Chinese \\
\hline & $+6230 G / G$ & Increased disease susceptibility & Japanese \\
\hline & $+6230 \mathrm{~A}$ & Decreased disease susceptibility & Japanese \\
\hline & $+49 \mathrm{~A} / \mathrm{A},+6230 \mathrm{~A} / \mathrm{A}$ & Increased relapse risk & Japanese \\
\hline Tumour necrosis factor- $\alpha$ (TNF- $\alpha)$ & $-893 \mathrm{~A}$ & Other organ involvement & Chinese \\
\hline Fc receptor-like 3 (FCRL3) & $-110 \mathrm{~A} / \mathrm{A}$ & Increased disease susceptibility & Japanese \\
\hline
\end{tabular}

in directing B cells to produce IgG4, IL-10 produced from Th2 cells and Tregs may be involved in hyperIgG4 in type 1 AIP [94].

Immune complex deposition is identifiable in the basement membrane of pancreatic ducts and acini $[95,96]$. These complexes consist of predominantly IgG4 and complement C3, with minor components of other IgG subclasses [96,97]. Given that IgG4 cannot form large immune complexes because of Fab-arm exchange, it remains to be clarified what is the role of IgG4 in immune complex formation, and how these depositions are involved in the pathogenesis of type 1 AIP.

\section{Conclusion}

Type 1 AIP is a pancreatic manifestation of IgG4-related disease. Serological, imaging, and histological examination are necessary for the diagnosis. Th2-dominant immunity and activated Tregs are supposed to be important for the immunopathogensis of the disease. Unique biological characteristics of IgG4 have been identified, but the exact role of IgG4 and the relevance of these targets in the induction of the disease remain to be clarified.

\begin{abstract}
Abbreviations
AIP: autoimmune pancreatitis; ANA: antinuclear antibody; CA: carbonic anhydrase; CT: computed tomography; ERCP: endoscopic retrograde cholangiopancreatography; FDG-PET: F-18 fluorodeoxyglucose positron emission tomography; GEL: granulocytic epithelial lesion; H. Pylori: Helicobacter pylori; LPSP: lymphoplasmacytic sclerosing pancreatitis; MRCP: magnetic resonance cholangiopancreatography; MRI: magnetic resonance imaging; Th: T-helper; Treg: regulatory T-cells; US: ultrasonography.
\end{abstract}

\section{Author details}

${ }^{1}$ Institute of Liver Studies, King's College Hospital and King's College London School of Medicine, Denmark Hill, London SE5 9RS, UK. ${ }^{2}$ Center for Health, Safety and Environmental Management, Shinshu University, 3-1-1 Asahi, Matsumoto 390-8621, Japan.

\section{Authors' contributions}

YZ and SK wrote the manuscript. All authors exchanged idea and approved the final version.

\section{Competing interests}

The authors declare that they have no competing interests.

Received: 24 August 2011 Accepted: 7 December 2011 Published: 7 December 2011

\section{References}

1. Yoshida K, Toki F, Takeuchi T, Watanabe S, Shiratori K, Hayashi N: Chronic pancreatitis caused by an autoimmune abnormality. Proposal of the concept of autoimmune pancreatitis. Dig Dis Sci 1995, 40:1561-1568.

2. Sarles H, Sarles JC, Muratore R, Guien C: Chronic inflammatory sclerosis of the pancreas-an autonomous pancreatic disease? Am J Dig Dis 1961, 6:688-698.

3. Kawaguchi K, Koike M, Tsuruta K, Okamoto A, Tabata I, Fujita N: Lymphoplasmacytic sclerosing pancreatitis with cholangitis: a variant of primary sclerosing cholangitis extensively involving pancreas. Hum Pathol 1991, 22:387-395.

4. Ectors N, Maillet B, Aerts R, Geboes K, Donner A, Borchard F, Lankisch P, Stolte M, Lüttges J, Kremer B, Klöppel G: Non-alcoholic duct destructive chronic pancreatitis. Gut 1997, 41:263-268.

5. Hamano H, Kawa S, Horiuchi A, Unno H, Furuya N, Akamatsu T, Fukushima M, Nikaido T, Nakayama K, Usuda N, Kiyosawa K: High serum lgG4 concentrations in patients with sclerosing pancreatitis. New England Journal of Medicine 2001, 344:732-738.

6. Hirano K, Komatsu Y, Yamamoto N, Nakai Y, Sasahira N, Toda N, Isayama H, Tada M, Kawabe T, Omata M: Pancreatic mass lesions associated with raised concentration of IgG4. Am J Gastroenterol 2004, 99:2038-2040.

7. Pezzilli $R$, Corinaldesi R: IgG4 as a serological marker of autoimmune pancreatitis: the latest news. JOP 2004, 5:531-533.

8. Sugumar A, Chari ST: Diagnosis and treatment of autoimmune pancreatitis. Curr Opin Gastroenterol 2010, 26:513-518.

9. Chari ST, Kloeppel G, Zhang L, Notohara K, Lerch MM, Shimosegawa T: Histopathologic and clinical subtypes of autoimmune pancreatitis: the honolulu consensus document. Pancreatology 2010, 10:664-672.

10. Hamano H, Kawa S, Ochi Y, Unno H, Shiba N, Wajiki M, Nakazawa K, Shimojo H, Kiyosawa K: Hydronephrosis associated with retroperitoneal fibrosis and sclerosing pancreatitis. Lancet 2002, 359:1403-1404.

11. Kamisawa T, Funata N, Hayashi Y, Tsuruta K, Okamoto A, Amemiya K, Egawa N, Nakajima H: Close relationship between autoimmune pancreatitis and multifocal fibrosclerosis. Gut 2003, 52:683-687.

12. Smyrk TC: Pathological features of IgG4-related sclerosing disease. Curr Opin Rheumatol 2011, 23:74-79.

13. Yamamoto $M$, Takahashi $H$, Ohara $M$, Suzuki C, Naishiro $Y$, Yamamoto $H$, Shinomura Y, Imai K: A new conceptualization for Mikulicz's disease as an IgG4-related plasmacytic disease. Mod Rheumatol 2006, 16:335-340.

14. Khosroshahi A, Stone JH: A clinical overview of lgG4-related systemic disease. Curr Opin Rheumatol 2011, 23:57-66.

15. Sah RP, Chari ST, Pannala R, Sugumar A, Clain JE, Levy MJ, Pearson RK, Smyrk TC, Petersen BT, Topazian MD, Takahashi N, Farnell MB, Vege SS: Differences in clinical profile and relapse rate of type 1 versus type 2 autoimmune pancreatitis. Gastroenterology 2010, 139:140-148.

16. Maire F, Le Baleur Y, Rebours V, Vullierme MP, Couvelard A, Voitot $H$, Sauvanet A, Hentic O, Lévy P, Ruszniewski P, Hammel P: Outcome of patients with type 1 or 2 autoimmune pancreatitis. Am J Gastroenterol 2011, 106:151-156

17. Notohara K, Burgart LJ, Yadav D, Chari S, Smyrk TC: Idiopathic chronic pancreatitis with periductal lymphoplasmacytic infiltration: clinicopathologic features of 35 cases. Am J Surg Pathol 2003, 27:1119-1127.

18. Zamboni G, Lüttges J, Capelli P, Frulloni L, Cavallini G, Pederzoli P, Leins A, Longnecker D, Klöppel G: Histopathological features of diagnostic and 
clinical relevance in autoimmune pancreatitis: a study on 53 resection specimens and 9 biopsy specimens. Virchows Arch 2004, 445:552-563.

19. Nishimori I, Tamakoshi A, Otsuki M, Research Committee on Intractable Diseases of the Pancreas, Ministry of Health, Welfare of Japan: Prevalence of autoimmune pancreatitis in Japan from a nationwide survey in 2002. J Gastroenterol 2007, 42(Suppl 18):6-8.

20. Deshpande V, Gupta R, Sainani N, Sahani DV, Virk R, Ferrone C, Khosroshahi A, Stone JH, Lauwers GY, Subclassification of autoimmune pancreatitis: a histologic classification with clinical significance. Am J Surg Pathol 2011, 35:26-35.

21. Klöppel G, Detlefsen S, Chari ST, Longnecker DS, Zamboni G: Autoimmune pancreatitis: the clinicopathological characteristics of the subtype with granulocytic epithelial lesions. J Gastroenterol 2010, 45:787-793.

22. Ryu JK, Chung JB, Park SW, Lee JK, Lee KT, Lee WJ, Moon JH, Cho KB, Kang DW, Hwang JH, Yoo KS, Yoo BM, Lee DH, Kim HK, Moon YS, Lee J, Lee HS, Choi HS, Lee SK, Kim YT, Kim CD, Kim SJ, Hahm JS, Yoon YB: Review of 67 patients with autoimmune pancreatitis in Korea: a multicenter nationwide study. Pancreas 2008, 37:377-385.

23. Park DH, Kim MH, Chari ST: Recent advances in autoimmune pancreatitis. Gut 2009, 58:1680-1689.

24. Kawa S, Hamano H, Kiyosawa K: Pancreatitis. St Louis: Academic Press; 4 2006.

25. Hyodo N, Hyodo T: Ultrasonographic evaluation in patients with autoimmune-related pancreatitis. J Gastroenterol 2003, 38:1155-1161

26. Nishino T, Toki F, Oyama H, Oi I, Kobayashi M, Takasaki K, Shiratori K: Biliary tract involvement in autoimmune pancreatitis. Pancreas 2005, 30:76-82.

27. Abraham SC, Cruz-Correa M, Argani P, Furth EE, Hruban RH, Boitnott JK Lymphoplasmacytic chronic cholecystitis and biliary tract disease in patients with lymphoplasmacytic sclerosing pancreatitis. Am J Surg Pathol 2003, 27:441-451.

28. Weber SM, Cubukcu-Dimopulo O, Palesty JA, Suriawinata A, Klimstra D, Brennan MF, Conlon K: Lymphoplasmacytic sclerosing pancreatitis: inflammatory mimic of pancreatic carcinoma. J Gastrointest Surg 2003, 7:129-137.

29. Nishimori I, Tamakoshi A, Kawa S, Tanaka S, Takeuchi K, Kamisawa T, Saisho H, Hirano K, Okamura K, Yanagawa N, Otsuki M: Influence of steroid therapy on the course of diabetes mellitus in patients with autoimmune pancreatitis: findings from a nationwide survey in Japan. Pancreas 2006, 32:244-248.

30. Ito $T$, Kawabe $K$, Arita $Y$, Hisano $T$, Igarashi H, Funakoshi A, Sumii T, Yamanaka T, Takayanagi R: Evaluation of pancreatic endocrine and exocrine function in patients with autoimmune pancreatitis. Pancreas 2007, 34:254-259.

31. Ko SB, Mizuno N, Yatabe Y, Yoshikawa T, Ishiguro H, Yamamoto A, Azuma S, Naruse S, Yamao K, Muallem S, Goto H: Corticosteroids correct aberrant CFTR localization in the duct and regenerate acinar cells in autoimmune pancreatitis. Gastroenterology 2010, 138:1988-1996.

32. Taniguchi T, Ko M, Seko S, Nishida O, Inoue F, Kobayashi H, Saiga T, Okamoto M, Fukuse T: Interstitial pneumonia associated with autoimmune pancreatitis. Gut 2004, 53:770.

33. Yoshimura Y, Takeda S, leki Y, Takazakura E, Koizumi H, Takagawa K: IgG4associated prostatitis complicating autoimmune pancreatitis. Intern Med 2006, 45:897-901

34. Kawa S, Okazaki K, Kamisawa T, Shimosegawa T, Tanaka M: Japanese consensus guidelines for management of autoimmune pancreatitis: II. Extrapancreatic lesions, differential diagnosis. J Gastroenterol 2010, 45:1264-1271

35. Yoshimura Y, Takeda S, leki Y, Takazakura E, Koizumi H, Takagawa K: IgG4associated prostatitis complicating autoimmune pancreatitis. Intern Med 2006, 45:897-901

36. Okazaki K, Kawa S, Kamisawa T, Naruse S, Tanaka S, Nishimori I, Ohara H, Ito $T$, Kiriyama $S$, Inui $K$, et al: Clinical diagnostic criteria of autoimmune pancreatitis: revised proposal. J Gastroenterol 2006, 41:626-631.

37. Chari ST, Smyrk TC, Levy MJ, Topazian MD, Takahashi N, Zhang L, Clain JE, Pearson RK, Petersen BT, Vege SS, Farnell MB: Diagnosis of autoimmune pancreatitis: the Mayo Clinic experience. Clin Gastroenterol Hepatol 2006, 4:1010-1016.

38. Takuma K, Kamisawa T, Tabata T, Inaba Y, Egawa N, Igarashi Y: Short-term and long-term outcomes of autoimmune pancreatitis. Eur I Gastroenterol Hepatol 2011, 23:146-152.
39. Okazaki K, Uchida K, Fukui T: Recent advances in autoimmune pancreatitis: concept, diagnosis, and pathogenesis. J Gastroenterol 2008, 43:409-418.

40. Okazaki K: Autoimmune pancreatitis: etiology, pathogenesis, clinical findings and treatment. The Japanese experience. JOP 2005, 6(Suppl 1):89-96.

41. Muraki T, Hamano H, Ochi Y, Komatsu K, Komiyama Y, Arakura N, Yoshizawa K, Ota M, Kawa S, Kiyosawa K: Autoimmune pancreatitis and complement activation system. Pancreas 2006, 32:16-21.

42. Rock B, Martins CR, Theofilopoulos AN, Balderas RS, Anhalt GJ, Labib RS, Futamura S, Rivitti EA, Diaz LA: The pathogenic effect of IgG4 autoantibodies in endemic pemphigus foliaceus (fogo selvagem). N Engl J Med 1989, 320:1463-1469.

43. van der Neut Kolfschoten M, Schuurman J, Losen M, Bleeker WK, MartínezMartínez P, Vermeulen E, den Bleker TH, Wiegman L, Vink T, Aarden LA, De Baets MH, van de Winkel JG, Aalberse RC, Parren PW: Anti-inflammatory activity of human IgG4 antibodies by dynamic Fab arm exchange. Science 2007, 317:1554-1557.

44. Kawa S, Kitahara K, Hamano H, Ozaki Y, Arakura N, Yoshizawa K, Umemura T, Ota M, Mizoguchi S, Shimozuru Y, Bahram S: A novel immunoglobulin-immunoglobulin interaction in autoimmunity. PLoS One 2008, 3:e1637.

45. Aalberse RC, Van Milligen F, Tan KY, Stapel SO: Allergen-specific lgG4 in atopic disease. Allergy 1993, 48:559-569.

46. Aalberse RC, Stapel SO, Schuurman J, Rispens T: Immunoglobulin G4: an odd antibody. Clin Exp Allergy 2009, 39:469-477.

47. Rispens T, Ooievaar-De Heer P, Vermeulen E, Schuurman J, van der Neut Kolfschoten M, Aalberse RC: Human lgG4 binds to lgG4 and conformationally altered lgG1 via Fc-Fc interactions. J Immunol 2009, 182:4275-4281.

48. Horiuchi A, Kawa S, Hamano H, Hayama M, Ota H, Kiyosawa K: ERCP features in 27 patients with autoimmune pancreatitis. Gastrointest Endosc 2002, 55:494-499.

49. Sugumar A, Levy MJ, Kamisawa T, J M Webster G, Kim MH, Enders F, Amin Z, Baron TH, Chapman MH, Church NI, Clain JE, Egawa N, Johnson GJ, Okazaki K, Pearson RK, Pereira SP, Petersen BT, Read S, Sah RP, Sandanayake NS, Takahashi N, Topazian MD, Uchida K, Vege SS, Chari ST: Endoscopic retrograde pancreatography criteria to diagnose autoimmune pancreatitis: an international multicentre study. Gut 2011, 60:666-670.

50. Irie H, Honda H, Baba S, Kuroiwa T, Yoshimitsu K, Tajima T, Jimi M, Sumii T, Masuda K, Autoimmune pancreatitis: CT and MR characteristics. AJR Am J Roentgenol 1998, 170:1323-1327.

51. Sahani DV, Kalva SP, Farrell J, Maher MM, Saini S, Mueller PR, Lauwers GY, Fernandez CD, Warshaw AL, Simeone JF: Autoimmune pancreatitis: imaging features. Radiology 2004, 233:345-352.

52. Fujinaga Y, Kadoya M, Kawa S, Hamano H, Ueda K, Momose M, Kawakami S, Yamazaki S, Hatta T, Sugiyama Y: Characteristic findings in images of extra-pancreatic lesions associated with autoimmune pancreatitis. Eur $\mathrm{J}$ Radiol 2009, 76:228-238.

53. Ito T, Nakano I, Koyanagi S, Miyahara T, Migita Y, Ogoshi K, Sakai H, Matsunaga S, Yasuda O, Sumii T, Nawata H: Autoimmune pancreatitis as a new clinical entity. Three cases of autoimmune pancreatitis with effective steroid therapy. Dig Dis Sci 1997, 42:1458-1468.

54. Kajiwara M, Kojima M, Konishi M, Nakagohri T, Takahashi S, Gotohda N, Hasebe T, Ochiai A, Kinoshita T: Autoimmune pancreatitis with multifocal lesions. J Hepatobiliary Pancreat Surg 2008, 15:449-452.

55. Takayama M, Hamano H, Ochi Y, Saegusa H, Komatsu K, Muraki T, Arakura N, Imai Y, Hasebe O, Kawa S: Recurrent attacks of autoimmune pancreatitis result in pancreatic stone formation. Am J Gastroenterol 2004, 99:932-937.

56. Muraki T, Hamano H, Ochi Y, Arakura N, Takayama M, Komatsu K, Komiyama Y, Kawa S, Uehara T, Kiyosawa K: Corticosteroid-responsive pancreatic cyst found in autoimmune pancreatitis. J Gastroenterol 2005, 40:761-766.

57. Nakajo M, Jinnouchi S, Fukukura Y, Tanabe H, Tateno R, Nakajo M: The efficacy of whole-body FDG-PET or PET/CT for autoimmune pancreatitis and associated extrapancreatic autoimmune lesions. Eur J Nucl Med Mol Imaging 2007, 34:2088-2095.

58. Ozaki Y, Oguchi K, Hamano H, Arakura N, Muraki T, Kiyosawa K, Momose M, Kadoya M, Miyata K, Aizawa T, Kawa S: Differentiation of autoimmune pancreatitis from suspected pancreatic cancer by fluorine-18 
fluorodeoxyglucose positron emission tomography. J Gastroenterol 2008, 43:144-151.

59. Sato M, Okumura T, Shioyama Y, Imura J: Extrapancreatic F-18 FDG accumulation in autoimmune pancreatitis. Ann Nucl Med 2008, 22:215-219.

60. Saegusa H, Momose M, Kawa S, Hamano H, Ochi Y, Takayama M, Kiyosawa K, Kadoya M: Hilar and pancreatic gallium-67 accumulation is characteristic feature of autoimmune pancreatitis. Pancreas 2003, 27:20-25.

61. Kim KP, Kim MH, Kim JC, Lee SS, Seo DW, Lee SK: Diagnostic criteria for autoimmune chronic pancreatitis revisited. World J Gastroenterol 2006, 12:2487-2496

62. Otsuki M, Chung JB, Okazaki K, Kim MH, Kamisawa T, Kawa S, Park SW Shimosegawa T, Lee K, Ito T, Nishimori I, Notohara K, Naruse S, Ko SB, Kihara Y, Research Committee of Intractable Pancreatic Diseases provided by the Ministry of Health, Labour and Welfare of Japan and the Korean Society of Pancreatobiliary Diseases: Asian diagnostic criteria for autoimmune pancreatitis: consensus of the Japan-Korea symposium on autoimmune pancreatitis. J Gastroenterol 2008, 43:403-408.

63. Shimosegawa T, Chari ST, Frulloni L, Kamisawa T, Kawa S, MinoKenudson M, Kim MH, Klöppel G, Lerch MM, Löhr M, Notohara K, Okazaki K, Schneider A, Zhang L: International consensus diagnostic criteria for autoimmune pancreatitis: guidelines of the international association of pancreatology. Pancreas 2011, 40:352-358.

64. Zhang L, Notohara K, Levy MJ, Chari ST, Smyrk TC: IgG4-positive plasma cell infiltration in the diagnosis of autoimmune pancreatitis. Mod Pathol 2007, 20:23-28

65. Ito T, Nishimori I, Inoue N, Kawabe K, Gibo J, Arita Y, Okazaki K, Takayanagi R, Otsuki M: Treatment for autoimmune pancreatitis: consensus on the treatment for patients with autoimmune pancreatitis in Japan. J Gastroenterol 2007, 42(Suppl 18):50-58.

66. Kamisawa T, Okazaki K, Kawa S, Shimosegawa T, Tanaka M: Japanese consensus guidelines for management of autoimmune pancreatitis: III. Treatment and prognosis of AIP. J Gastroenterol 2010, 45:471-477.

67. Kamisawa T, Shimosegawa T, Okazaki K, Nishino T, Watanabe H, Kanno A, Okumura F, Nishikawa T, Kobayashi K, Ichiya T, Takatori H, Yamakita K, Kubota K, Hamano H, Okamura K, Hirano K, Ito T, Ko SB, Omata M: Standard steroid treatment for autoimmune pancreatitis. Gut 2009, 58:1504-1507.

68. Pannala R, Chari ST: Corticosteroid treatment for autoimmune pancreatitis. Gut 2009, 58:1438-1439.

69. Matsushita M, Ikeura T, Fukui T, Uchida K, Okazaki K: Refractory autoimmune pancreatitis: azathioprine or steroid pulse therapy? Am J Gastroenterol 2008, 103:1834.

70. Ghazale A, Chari ST, Zhang L, Smyrk TC, Takahashi N, Levy MJ, Topazian MD, Clain JE, Pearson RK, Petersen BT, Vege SS, Lindor K, Farnell MB: Immunoglobulin G4-associated cholangitis: clinical profile and response to therapy. Gastroenterology 2008, 134:706-715.

71. Topazian M, Witzig TE, Smyrk TC, Pulido JS, Levy MJ, Kamath PS, Chari ST: Rituximab therapy for refractory biliary strictures in immunoglobulin G4associated cholangitis. Clin Gastroenterol Hepatol 2008, 6:364-366.

72. Kawakami H, Kuwatani M, Shinada K, Yamato H, Hirano S, Kondo S, Yonemori A, Itoh T, Matsuno Y, Asaka M: Autoimmune pancreatitis associated with hemorrhagic pseudocysts: a case report and literature review. Intern Med 2008, 47:603-608.

73. Nishimura T, Masaoka T, Suzuki $H$, Aiura K, Nagata H, Ishii H: Autoimmune pancreatitis with pseudocysts. J Gastroenterol 2004, 39:1005-1010.

74. Zen Y, Sawazaki A, Miyayama S, Notsumata K, Tanaka N, Nakanuma Y: A case of retroperitoneal and mediastinal fibrosis exhibiting elevated levels of lgG4 in the absence of sclerosing pancreatitis (autoimmune pancreatitis). Hum Pathol 2006, 37:239-243.

75. Zen Y, Harada K, Sasaki M, Sato Y, Tsuneyama K, Haratake J, Kurumaya H, Katayanagi K, Masuda S, Niwa H, Morimoto H, Miwa A, Uchiyama A, Portmann BC, Nakanuma Y: IgG4-related sclerosing cholangitis with and without hepatic inflammatory pseudotumor, and sclerosing pancreatitisassociated sclerosing cholangitis: do they belong to a spectrum of sclerosing pancreatitis? Am J Surg Pathol 2004, 28:1193-1203.

76. Zen Y, Nakanuma Y: IgG4-related disease: a cross-sectional study of 114 cases. Am J Surg Pathol 2010, 34:1812-1819.

77. Kawa S, Ota M, Yoshizawa K, Horiuchi A, Hamano H, Ochi Y, Nakayama K, Tokutake Y, Katsuyama Y, Saito S, Hasebe O, Kiyosawa K: HLA DRB10405-
DQB10401 haplotype is associated with autoimmune pancreatitis in the Japanese population. Gastroenterology 2002, 122:1264-1269.

78. Park do H, Kim MH, Oh HB, Kwon OJ, Choi YJ, Lee SS, Lee TY, Seo DW, Lee SK: Substitution of aspartic acid at position 57 of the DQbeta1 affects relapse of autoimmune pancreatitis. Gastroenterology 2008, 134:440-446

79. Chang MC, Chang YT, Tien YW, Liang PC, Jan IS, Wei SC, Wong JM: T-cell regulatory gene CTLA-4 polymorphism/haplotype association with autoimmune pancreatitis. Clin Chem 2007, 53:1700-1705.

80. Umemura T, Ota M, Hamano H, Katsuyama Y, Kiyosawa K, Kawa S: Genetic association of $\mathrm{Fc}$ receptor-like 3 polymorphisms with autoimmune pancreatitis in Japanese patients. Gut 2006, 55:1367-1368.

81. Umemura T, Ota M, Hamano H, Katsuyama Y, Muraki T, Arakura N, Kawa S, Kiyosawa K: Association of autoimmune pancreatitis with cytotoxic Tlymphocyte antigen 4 gene polymorphisms in Japanese patients. Am J Gastroenterol 2008, 103:588-594.

82. Okazaki K, Uchida K, Ohana M, Nakase H, Uose S, Inai M, Matsushima Y, Katamura K, Ohmori K, Chiba T: Autoimmune-related pancreatitis is associated with autoantibodies and a Th1/Th2-type cellular immune response. Gastroenterology 2000, 118:573-581.

83. Nishimori I, Miyaji E, Morimoto K, Nagao K, Kamada M, Onishi S: Serum antibodies to carbonic anhydrase IV in patients with autoimmune pancreatitis. Gut 2005, 54:274-281.

84. Asada M, Nishio A, Uchida K, Kido M, Ueno S, Uza N, Kiriya K, Inoue S, Kitamura H, Ohashi S, Tamaki H, Fukui T, Matsuura M, Kawasaki K, Nishi T, Watanabe N, Nakase H, Chiba T, Okazaki K: Identification of a novel autoantibody against pancreatic secretory trypsin inhibitor in patients with autoimmune pancreatitis. Pancreas 2006, 33:20-26.

85. Löhr JM, Faissner R, Koczan D, Bewerunge P, Bassi C, Brors B, Eils $R$, Frulloni L, Funk A, Halangk W, Jesnowski R, Kaderali L, Kleeff J, Krüger B, Lerch MM, Lösel R, Magnani M, Neumaier M, Nittka S, Sahin-Tóth M, Sänger J, Serafini S, Schnölzer M, Thierse HJ, Wandschneider S, Zamboni G, Klöppel G: Autoantibodies against the exocrine pancreas in autoimmune pancreatitis: gene and protein expression profiling and immunoassays identify pancreatic enzymes as a major target of the inflammatory process. Am J Gastroenterol 2010, 105:2060-2071.

86. Guarneri F, Guarneri C, Benvenga S: Helicobacter pylori and autoimmune pancreatitis: role of carbonic anhydrase via molecular mimicry? J Cell Mol Med 2005, 9:741-744.

87. Frulloni L, Lunardi C, Simone R, Dolcino M, Scattolini C, Falconi M, Benini L, Vantini I, Corrocher R, Puccetti A: Identification of a novel antibody associated with autoimmune pancreatitis. N Engl J Med 2009, 361:2135-2142.

88. Zen Y, Fujii T, Harada K, Kawano M, Yamada K, Takahira M, Nakanuma Y: Th2 and regulatory immune reactions are increased in immunoglobin G4-related sclerosing pancreatitis and cholangitis. Hepatology 2007, 45:1538-1546.

89. Miyake K, Moriyama M, Aizawa K, Nagano S, Inoue Y, Sadanaga A, Nakashima H, Nakamura S: Peripheral CD4+ T cells showing a Th2 phenotype in a patient with Mikulicz's disease associated with lymphadenopathy and pleural effusion. Mod Rheumatol 2008, 18:86-90

90. Kudo-Tanaka E, Nakatsuka S, Hirano T, Kawai M, Katada Y, Matsushita M, Ohshima S, Ishii M, Miyatake K, Tanaka T, Saeki Y: A case of Mikulicz's disease with Th2-biased cytokine profile: possible feature discriminable from Sjögren's syndrome. Mod Rheumatol 2009, 19:691-695.

91. Akitake R, Watanabe T, Zaima C, Uza N, Ida H, Tada S, Nishida N, Chiba T: Possible involvement of T helper type 2 responses to Toll-like receptor ligands in IgG4-related sclerosing disease. Gut 2010, 59:542-545.

92. Suzuki K, Tamaru J, Okuyama A, Kameda H, Amano K, Nagasawa H, Nishi E, Yoshimoto K, Setoyama Y, Kaneko K, Osada H, Honda N, Sasaki Y, Itoyama S, Tsuzaka K, Takeuchi T: IgG4-positive multi-organ lymphoproliferative syndrome manifesting as chronic symmetrical sclerosing dacryo-sialadenitis with subsequent secondary portal hypertension and remarkable IgG4-linked IL-4 elevation. Rheumatology (Oxford) 2010, 49:1789-1791.

93. Miyoshi H, Uchida K, Taniguchi T, Yazumi S, Matsushita M, Takaoka M, Okazaki K: Circulating naïve and CD4+CD25high regulatory T cells in patients with autoimmune pancreatitis. Pancreas 2008, 36:133-140.

94. Zen Y, Nakanuma Y: Pathogenesis of IgG4-related disease. Curr Opin Rheumatol 2011, 23:114-18. 
95. Deshpande V, Chicano S, Finkelberg D, Selig MK, Mino-Kenudson M, Brugge WR, Colvin RB, Lauwers GY: Autoimmune pancreatitis: a systemic immune complex mediated disease. Am J Surg Pathol 2006, 30:1537-1545.

96. Detlefsen S, Bräsen JH, Zamboni G, Capelli P, Klöppel G: Deposition of complement C3c, immunoglobulin (lg) G4 and IgG at the basement membrane of pancreatic ducts and acini in autoimmune pancreatitis. Histopathology 2010, 57:825-835.

97. Cornell LD, Chicano SL, Deshpande V, Collins AB, Selig MK, Lauwers GY, Barisoni L, Colvin RB: Pseudotumors due to IgG4 immune-complex tubulointerstitial nephritis associated with autoimmune pancreatocentric disease. Am J Surg Pathol 2007, 31:1586-1597.

doi:10.1186/1750-1172-6-82

Cite this article as: Zen et al:: Type 1 autoimmune pancreatitis. Orphanet Journal of Rare Diseases 2011 6:82

Submit your next manuscript to BioMed Central and take full advantage of:

- Convenient online submission

- Thorough peer review

- No space constraints or color figure charges

- Immediate publication on acceptance

- Inclusion in PubMed, CAS, Scopus and Google Scholar

- Research which is freely available for redistribution

Submit your manuscript at www.biomedcentral.com/submit 